\title{
Numerical Simulation Analysis of Hydrothermal Change of Subgrade by Seepage Drainage Geogrid Under the Effect of Asphalt Mixture Freeze-Thaw Action
}

\author{
Fang WANG ${ }^{\text {a,1 }}$ \\ ${ }^{a}$ Shanti Transportation Survey \& Design Institute Co., Ltd, China
}

\begin{abstract}
In seasonal frozen soil area, the engineering problems caused by the excessive moisture content of the subgrade soil are widespread. In view of this phenomenon, author proposes to employ a new type of research and development of the seepage drainage geogrid (SDG) to cool and drain the soil. Through indoor model test, after two freeze-thaw cycles, the experimental comparison of the size and laying method of various SDG was carried out. The test result shows that the model with a natural grit layer has the most drainage effect. While, the model contains two layers of interconnected grilles has the best cooling effect. The indoor model test is simulated by accurate numerical simulation. The simulation results are compared with the indoor test results. The fitting results of the two results are very high, which provides theoretical support and data guarantee for the application of seepage drainage grille to strengthen the roadbed in the cold road.
\end{abstract}

Keywords. Asphalt mixture seasonal frozen soil, seepage drainage geogrid, numerical simulation, cool and drain.

\section{Introduction}

The subgrade is the foundation of the whole road structure, and its stability directly affects the function and use of the road structure. The subgrade can only maintain the cohesiveness of the subgrade soil particles within a certain moisture content range to ensure that the pavement does not deform and damage [1-3]. The high water content of subgrade will seriously affect its stability and service life, especially wet and over-wet soil subgrade, which are affected by factors such as surface water (rain and snow melting, etc.), groundwater [4-7]. It has a great influence on the stability and durability of the pavement structure [8-10].

In view of the problem of excessive moisture content of subgrade soil in seasonal frozen soil areas, the author used a new type of SDG developed by the Cold Region Science and Engineering Research Institute of Northeast Forestry University.

\footnotetext{
1 Fang WANG, Shanti Transportation Survey \& Design Institute Co., Ltd, China; E-mail: wangfang_3212021@163.com.
} 


\section{Numerical Simulation Analysis}

\subsection{Introduction of Numerical Simulation Technology}

As early as the 1960s, American scholar Kraft applied finite element to the stability analysis of earth-rock dams. In the past half century, in the field of geotechnical engineering, numerical simulation has been greatly developed and a lot of complicated engineering problems were well solved by this kind of technology. Also, with the development of computers, more complex large-scale model tests and some geotechnical problems which are too resource-intensive and difficult to make into solid models can be solved in this way. Computer's appearance and development not only saves a lot of valuable time and resources, but also provides a large room for numerical simulation's development.

Numerical simulation has many advantages appling to the experimental research of geotechnical engineering, especially for the soil's indoor model test under freezing and thawing cycles, the whole text time can be greatly shortened, and the test conditions which are difficult to apply in the room can be solved at the same time. Also, different kinds of test conditions can be repeated multiple times, the temperature and moisture changes can be found and the results and assignment conditions of the calculation model can be verified in a short time.

\subsection{Establishment of SDG Model}

Since the cross section of the grid tube is circular, the meshing density of the soil around the circular tube is very large and the number is large. In order not to affect the calculation parameters of the model and simplify the calculation, also mechanical factors are not considered in this experiment, the cross section of the grid tube is changed to rectangle, but the contact area of the gird tube and the soil still maintains, which causes a $20 \%$ reduction in the model's volume. Comparing the results between indoor model test and numerical simulation, it is found that the volume change of the SDG has little effect on the soil temperature and water content. The mesh of the seepage drainage grid is divided into tetrahedral units, and the total number of divided domain units is 66,113 . The graphs of equivalent grating and model soil mesh division are shown in figure 1 and figure 2.

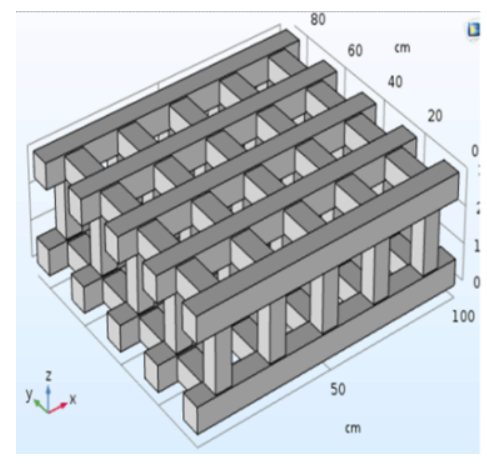

Figure 1. The graph of equivalent grating.

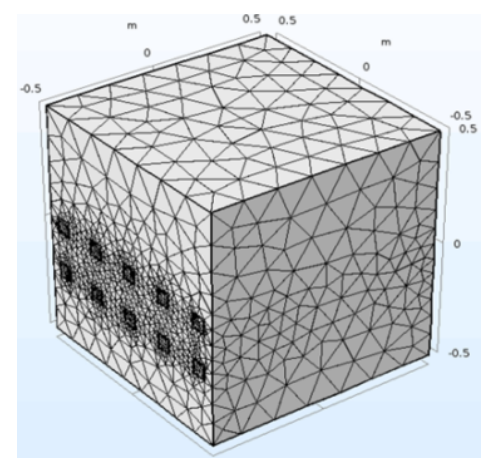

Figure 2. Model soil mesh division. 


\subsection{Selection of Parameters}

For the simulation of moisture and heat transfer, some parameters (such as thermal conductivity and specific heat capacity) are indispensable. These parameters have been obtained through previous laboratory tests, as shown in the table 1 and table 2.

Table 1. Parameters of heat conduction and heat capacity in the simulation.

\begin{tabular}{clllllll}
\hline$\rho_{\mathrm{d}}$ & $W$ & $C_{\mathrm{u}}$ & $C_{\mathrm{f}}$ & $\lambda_{\mathrm{u}}$ & $\lambda_{\mathrm{f}}$ & $\alpha_{\mathrm{u}}$ & $\alpha_{\mathrm{f}}$ \\
\hline$\left(\mathrm{kg} / \mathrm{m}^{3}\right)$ & $(\%)$ & $\mathrm{kJ} /\left(\mathrm{m}^{3} \cdot \mathrm{K}\right)$ & & {$[\mathrm{W} /(\mathrm{m} \cdot \mathrm{K})]$} & & $\left(\times 10^{3} \mathrm{~m}^{2} / \mathrm{h}\right)$ & \\
\hline 1581 & 23 & 2843.8 & 2459.1 & 1.26 & 1.59 & 1.59 & 2.49 \\
1600 & 25 & 3011.0 & 2375.4 & 1.28 & 1.80 & 1.52 & 2.73 \\
\hline
\end{tabular}

Table 2. Parameters of moisture in the simulation.

\begin{tabular}{lllllll}
\hline $\begin{array}{l}\text { Freezing } \\
\text { point }\end{array}$ & $\begin{array}{l}\text { Melting } \\
\text { point }\end{array}$ & $\begin{array}{l}\text { Water } \\
\text { conductivity }\end{array}$ & Water density & Ice density & Latent heat & $\begin{array}{l}\text { Initial moisture } \\
\text { content }\end{array}$ \\
\hline$\left({ }^{\circ} \mathrm{C}\right)$ & & $(\mathrm{m} / \mathrm{s})$ & $\left(\mathrm{kg} / \mathrm{m}^{3}\right)$ & & $(\mathrm{kJ} / \mathrm{kg})$ & $\left(\mathrm{m}^{3} / \mathrm{m}^{3}\right)$ \\
\hline-3 & 0.5 & $6.5 \times 10^{-8}$ & 1000 & 900 & 334.7 & 0.3 \\
\hline
\end{tabular}

\subsection{Selection of Controlling Equation}

Solving the multiphysics coupling is essentially the solution of partial differential equations, since COMSOL Multiphysics has many embedded controlling equations in water and heat transfer module, it is important to select the governing equation according to the actual conditions.

\subsubsection{Controlling Equation of Heat Transfer}

In order to solve the soil temperature field, it is necessary to establish a differential equation that can describe the heat conduction problem which must be based on Fourier's law and the law of conservation of energy. For the purpose of simplifing this problem, it is assumed that the soil is homogeneous and isotropic, and its thermal conductivity $\lambda$, specific heat $\mathrm{Cd}$ and density $\rho$ are treated as constants. When there is no heat flow distribution in the soil, the Fourier governing equation can be reduced to the following form:

$$
\frac{\partial \theta}{\partial t}=\frac{\lambda}{C_{\rho}}\left(\frac{\partial^{2} \theta}{\partial x^{2}}+\frac{\partial^{2} \theta}{\partial y^{2}}+\frac{\partial^{2} \theta}{\partial z^{2}}\right)
$$

The description of the heat transfer in soil must also list the conditions that meet the specific conditions of the test: initial conditions - indicating the temperature distribution of the soil at the beginning of the process; boundary conditions - the mutual heat exchange between the soil and the surrounding medium at the geometric boundary effect. The initial conditions and boundary conditions are collectively referred to boundary conditions. The complete mathematical description of any specific heat transfer problem should include the thermal differential equation and the boundary condition. For the problem of stable heat transfer, the initial conditions are meaningless. In this test, the process of temperature rising is an unsteady transfer problem, and when the temperature lowers, the heat transfer problem is stabilized, but the temperature rises 
and falls in the grid is unsteady, therefore, solving this problem of unsteady temperature conduction is most suitable.

\subsubsection{Controlling Equation of Water Migration}

There are two kinds of seepage modes for water migration in soil, stable seepage and unsteady seepage. Stable seepage: The unfrozen water migrates in frozen soil under constant temperature gradient, the migration amount does not change with time, and it belongs to stable seepage. Unsteady seepage: Under the condition of the freezing front and the temperature gradient change in the frozen soil, the migration amount changes with time, which is an unsteady seepage condition. According to the temperature change and distribution of indoor test, water migration belongs to unsteady seepage, which needs to be solved by hydro-thermal coupling equation. Harlan model and Taylor model are commonly used.

Harlan Model:

$$
\frac{\partial}{\partial x}\left(\lambda \frac{\partial \theta}{\partial x}\right)=c \rho \frac{\partial \theta}{\partial t}-L \frac{\partial W_{1}}{\partial t}
$$

Water flow equation:

$$
\begin{aligned}
& \frac{\partial}{\partial x}\left(K \frac{\partial \varphi}{\partial x}\right)=\frac{\partial W_{w}}{\partial t}+\frac{\rho_{i}}{\rho_{\mathrm{w}}} \frac{\partial W_{\mathrm{i}}}{\partial t} \\
& \left(c \rho+L \frac{\partial W_{\mathrm{W}}}{\partial T}\right) \frac{\partial \theta}{\partial t}=\frac{\partial}{\partial x}\left(\lambda \frac{\partial \theta}{\partial x}\right)+L\left(K \frac{\partial \varphi}{\partial x}\right)
\end{aligned}
$$

Taylor and Luthin Model:

$$
\frac{\partial}{\partial x}\left(D \frac{\partial W_{w}}{\partial x}\right)=\frac{\partial W_{w}}{\partial t}+\frac{\rho_{i}}{\rho_{w}} \frac{\partial W_{i}}{\partial t}
$$

Where: $\lambda$ is the thermal conductivity; $\mathrm{c}$ is the specific heat; $\rho$ is the density; $\mathrm{L}$ is the latent heat of melting of ice; $\theta$ is the temperature; $x$ is the coordinate; $t$ is the time; Wi is the ice content; $\mathrm{Ww}$ is the volumetric water content; $\mathrm{K}$ is The coefficient of moisture conductivity; $\varphi$ is the soil water potential; $\mathrm{D}$ is the water diffusion coefficient.

For the flux of unfrozen water in frozen soil, using Darcy's law for unsaturated soil motion:

$$
Q=-D_{w}(\theta) W_{u}
$$

The water movement in frozen soil and unfrozen soil can be described by a consistent equation, which is convenient for unified calculation.

For frozen soil and unfrozen soil, the main role of water is the phase of water. Therefore, the changes in density, thermal conductivity, volumetric heat capacity, temperature and water content before and after the water phase change are known. When the properties of the frozen soil are uniform and the temperature is constant:

$$
\rho C_{\mathrm{pu}} \cdot \nabla T+\nabla \cdot \mathrm{q}=Q+Q_{p}+Q_{\mathrm{vd}}
$$


Where:

$$
\begin{aligned}
& \mathrm{q}=\lambda \nabla T \\
& \rho=\theta \rho_{\mathrm{u}}+(1-\theta) \rho_{\mathrm{f}} \\
& C_{y}=\frac{1}{\rho}\left(\theta_{\mathrm{u}} \rho_{\mathrm{u}} C_{\mathrm{u}}+(1-\theta) \rho_{\mathrm{f}}\right)+L \frac{\partial \alpha_{\mathrm{m}}}{\partial T} \\
& \lambda=\theta \lambda_{\mathrm{u}}+(1-\theta) \lambda_{\mathrm{f}} \\
& \frac{\partial \mathrm{ol}_{\mathrm{m}}}{\partial T}=\frac{1}{2} \cdot \frac{(1-\theta) \rho_{\mathrm{f}}-\theta \rho_{\mathrm{u}}}{\theta \rho_{\mathrm{u}}+(1-\theta) \rho_{\mathrm{f}}}
\end{aligned}
$$

When temperature changes with time:

$$
\rho C_{p} \frac{\partial T}{\partial t}+\rho C_{p l} \cdot \nabla T+\nabla \cdot \mathrm{q}=Q+Q_{p}+Q_{\mathrm{ud}}
$$

\subsection{Solution of Phase Change}

When the soil is frozen or melted, it will be accompanied by phase change. When the soil phase changes, the soil absorbs energy, but the temperature does not change. The latent heat in the whole phase transition cannot be Neglect, so how to deal with the phase change process is particularly important.

This time value simulation is to insert a step function for the phase change processing, locate the parameter bar, type the position of the center point in the position text box, and then draw a smooth curve. The phase change material defined is assigned to the model, the phase change material 1 selects ice, the phase change material selects water, and the latent heat of phase change is $333.5 \mathrm{KJ} / \mathrm{Kg}$. Through the above series of processing methods for phase change, the existence of phase transition can be accurately reflected in the simulation.

\section{Numerical Simulation Analysis of Temperature during Cooling}

According to the basic parameter values and the assignment conditions determined by the indoor test, the calculation model is numerically solved. When the external environment is sealed and there is no air flow in the grating tube, the temperature change of the section in the post-model specimen is shown in figures 3 and 4 after cooling for 72 hours (3d) and 720 hours (30d). 


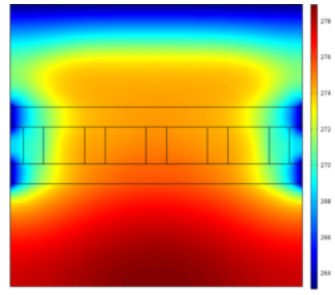

Figure 3. The temperature after 72 hours.

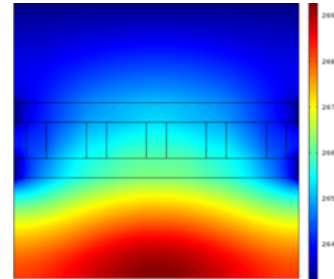

Figure 4. The temperature after 720 hours.

It can be seen from the figures 3 and 4 that the convective heat transfer is symmetrically distributed on both sides of the grid tube hole. After the external temperature drops to negative temperature, the temperature at the center of the soil drops only to $-7.5^{\circ} \mathrm{C}$ after 15 days without air flow which does not match with the results tested by indoor experiment. After increasing the air flow rate of $0.3 \mathrm{~m} / \mathrm{s}$, temperature of the whole model drops to below $-9^{\circ} \mathrm{C}$ after 720 hours which is similar to the actual cooling situation. Figure 5 shows that during the cooling process, there must be convective heat transfer between the grid tube and the soil around the tube in the SDG. The temperature change after 720 hours can be determined by the actual situation of air flow in the pipe during the cooling process.

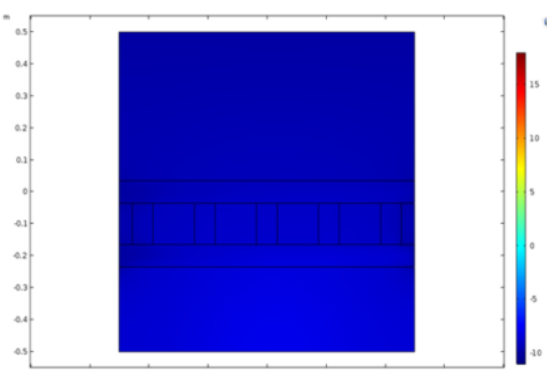

Figure 5. The temperature after 720 hours with flow.

After increasing the wind speed of $0.3 \mathrm{~m} / \mathrm{s}$ in the tube, the relationships between temperature and time. The results are as follows:

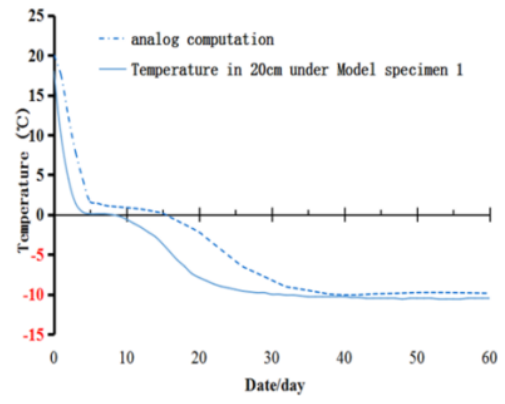

Figure 6. The $20 \mathrm{~cm}$ temperature under grille.

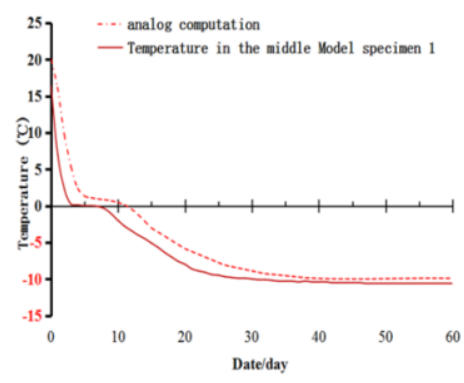

Figure 7. Grid level temperature. 


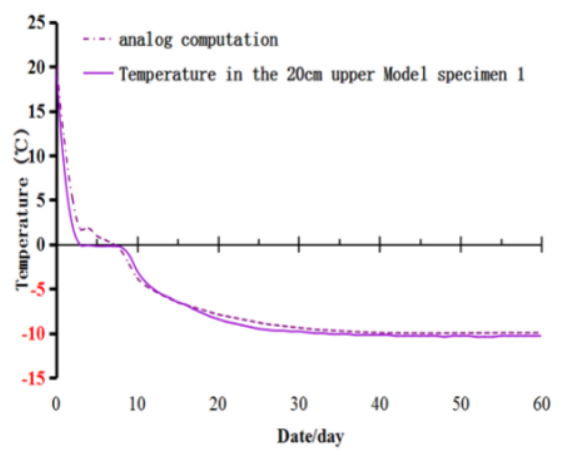

Figure 8. The $20 \mathrm{~cm}$ temperature on the grille.

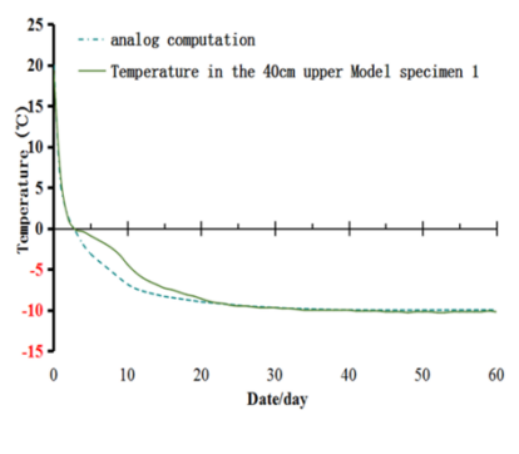

Figure 9. The $40 \mathrm{~cm}$ temperature on the grille.

The temperature versus time curve of the different measurement points in the finite element calculation results and the indoor model test results shown in figure 6, figure 7, figure 8 and figure 9 . The temperature value of the indoor model test results is basically in the state of zero slope of the curve during the phase transition, and the surface soil is also near zero. Very short phase change process. The temperature change of the $20 \mathrm{~cm}$ under the grid and the grid layer under the finite element simulation is lagging behind the temperature value measured by the test, and the temperature transition region of the $40 \mathrm{~cm}$ position on the grid is faster and the phase transition is not obvious.

The reason for the analysis is that the lower part of the grid layer, due to the action of the bottom water source, the capillary water rising channel is still migrating from the "unfrozen zone" to the "freezing zone" before being frozen and cut, and the soil box The thermal insulation layer is not completely adiabatic, and the thermal insulation layer defined by the numerical simulation is completely adiabatic. Therefore, the numerical simulation of the cooling and phase transformation of the lower part of the grid layer of the model specimen is delayed behind the measured variation. For the $40 \mathrm{~cm}$ position on the grille, there is a water-repellent layer at the $50 \mathrm{~cm}$ position on the grille, and $10 \mathrm{~cm}$ thick soil covering the water-repellent layer. Therefore, when the water freezes, it accumulates on the surface of the water-repellent layer $10 \mathrm{~cm}$ away from the surface. At the same time, the density and water content of the actual soil model are not absolutely isotropic, so there is a certain difference between the numerical calculation value and the measured value for the temperature change of the surface soil. However, from the comparison of the overall and local temperature values, the fitting degree of temperature with time is still very high.

\section{Conclusion}

1) The mechanism of water migration inside the soil is the migration of the film water and the capillary water between the particles under the condition of external temperature change, under the combined action of soil water potential, temperature and gravity, and the seepage drainage geogrid The drainage mechanism of the grid once again validates the theory of soil water migration theory. The temperature regulation and drainage effect of the entire seepage drainage geogrid is essentially the mass transfer heat transfer process of soil particles, moisture and air as energy transmission medium. Under the condition of external atmospheric temperature change, energy 
transfer and exchange between materials is carried out. The resulting temperature change and water change in the soil further redistribute the temperature field and the water field in the soil. This redistribution enables the roadbed soil to reduce the freezing damage caused by water.

2) Using COMSOL Multiphysics finite element software to solve the equations under given conditions, the formula of soil water heat for laying the drainage geogrid is obtained. After comparison with the experimental data, the fitting degree is very high.

\section{References}

[1] Yu QH, Fan K, Qian J, Guo L, You YH. Key issues of highway construction in permafrost regions in China. Sci. Sin. Tech. 2014 Apr; 44(4): 425-432.

[2] Zhou MZ. About our country frozen soil roadbed processing method of course. Sichuan Building Materials. 2018 Apr; 44(4): 156-157.

[3] Heitman JL, Horton R, Ren T, Nassar IN, Davis DD. A test of coupled soil heat and water transfer prediction under transient boundary temperatures. Soil Science Society of America Journal. 2008 Sep; 72(5): 1197-1207.

[4] Liu G, Wang Sh J, Jin L, Dong YH, Yuan K. Applicable effect of thermosyphon subgrades in permafrost regions. Journal of Traffic and Transportation Engineering. 2016 Aug; 16(4): 59-66.

[5] Wang SJ, Huang XM, Hou SG. Numerical analyses of pavement deformation and stress in permafrost regions. Journal of Glaciology and Geocryology. 2006 Apr; 28(2): 217-222.

[6] Wu QB and Niu FJ. Permafrost changes and engineering stability in Qinghai-Xizang Plateau. Chin. Sci. Bull. 2013 Apr; 58(10):1079-1094.

[7] Ma W, Mu YH, Wu QB, Sun ZZ, Liu YZ. Characteristics and mechanisms of embankment deformation along the Qinghai-Tibet Railway in permafrost regions. Cold Regions Science and Technology. 2011 Feb; 67(3): 178-186.

[8] Zhang MY, Lai YM, Zhang JM, Sun ZZ. Numerical study on cooling characteristics of two phase closed thermosyphon embankment in permafrost regions. Cold Regions Science and Technology. 2011 Oct; 65(2): 203-210.

[9] Dong YB, Lai YM, Xu XT, Zhang SM. Using perforated ventilation ducts to enhance the cooling effect of crushed-rock interlayer on embankments in permafrost regions. Cold Regions Science and Technology. 2010 Mar; 62(1): 76-82.

[10] Wang WH, Wu TH, Li R, Xie CW, Zhu XF. An overview of advances on moisture migration of the active layer in permafrost regions of the Qinghai-Tibetan Plateau. Journal of Northwest Normal University (Natural Science). 2017 Nov; 53(1): 102-111. 